" in its beginnings . . . is difficult to detect but easy to cure, but if it remains untreated it becomes easy to detect and difficult to cure," and in his own words, "Thanks to tuberculin the early diagnosis and arrest of pulmonary tuberculosis are no longer. matters of difficulty." According to Dr. Sutherland " none of the early symptoms, physical signs on X-ray appearances are in themselves, either singly or combined, diagnostic of pulmonary tuberculosis, and the key to their interpretation is in the tuberculin tests."

Dr. Sutherland is a firm believer in the reliability of the subcutaneous injection of tuberculin in the diagnosis of active tuberculosis, and like most advocates of tuberculin therapy for pulmonary disease wishes to get the case in the so-called pre-bacillary stage, i.e., before the sputum examinations are positive. Although he makes very high claims for this method of treatment, the does not bring forward any statistical evidence of his own but supports his contention by quoting the findings of another tuberculin enthusiast, who apparently gets better results in all varieties of pulmonary tuberculosis than by any other method, residence in a sanatorium included.

\section{AN INTRODUCTION TO HYGIENE.}

By W. ROBERTSON, M.D., D.P.H., F.R.C.P.(Eng.). 2nd Edition: Edinburgh. E. \& S. Livingstone : 1936. Price 8/6 net.

This second edition of Dr. Robertson's Hygiene is considerably enlarged, though still a small manual, and much of the sketchiness of the first edition has been remedied. The illustrations are very good and practically self-explanatory to the reader. Everywhere the book is informed by the author's wide experience of actual public health work and questions, and this serves to enliven the drearier parts of study, as where he states that "one is confronted with rows upon rows of three and four storied one-pattern blocks of tenements which have a close resemblance to barracks. This uninspiring system has been aptly called 'warehousing the people" ".
The chapter on Industrial Diseases is meagre; and under water supply one is surprised that no use is made of Houston's dictum that adequate storage results in sedimentation, devitalisation, and equalisation. The time-honoured term of "upland surface water" is still well worth retention. There are a number of typographical errors which will require correction, e.g., p. 188 , "washwork" for "meshwork" ; on p. 220 "Being carbonates" for "Becoming carbonates" ; and p. 138, line 2 from foot, "of moisture" is omitted after "6 cubic feet". Again the equation on p. 228 has the multiplication sign instead of plus one, and one such equation will not solve the problem.

\section{AGENTS OF DISEASE AND HOST RESISTANCE.}

\section{Frederick P. Gay and Associates.}

Baillière, Tindall \& $\operatorname{Cos}, 7 \& 8$, Henrietta Street, Covent Garden, W.C.2. Price 45/-. 1936.

"Agents of Disease and Host Resistance " is a large volume compiled by Frederick P. Gay and several associates, most of whom are past or present members of the Department of Bacteriology of Columbia University, New York. It is not the sort of book which anyone is likely to try to read through from page 1 to page 1,560 but it will prove to be a valuable source of reference, particularly because most of the articles have been written by authors with special experience of the subject on which they have written. This has proved to be the case during the time when this book has been waiting to be reviewed. When turned to for reference purposes there has always been found a little bit more than could be discovered in other smaller text books. It must be assumed that the title of the book was agreed on by the twenty authors who have united to produce it, but it is certainly a peculiar choice. The natural title would seem to be "Medical Microbiology and Immunity." This is certainly what it is all about, and a much better description of the contents than "Agents of Disease and Host Resistance." 